\title{
NUEVOS ESPACIOS PARA LA CONSIDERACIÓN DE LA VÍCTIMA Y SUS INTERESES EN EL PROCESO PENAL ESPAÑOL ${ }^{1-2}$
}

\section{NEW SPACES TO CONSIDER THE VICTIM AND HIS INTERESTS IN SPANISH CRIMINAL PROCEDURE}

Belén Hernández Moura

Profesora de Derecho Procesal en la Universidad Carlos III de Madrid, España. E-mail: behernan@der-pu.uc3m.es

RESUMEN: El trabajo analiza el cambio en la concepción tradicional del proceso penal en los últimos tiempos. La protección de las víctimas empieza a ganar más espacio, lo que exige una reflexión profunda en términos de calidad del sistema de Justicia; exige un proceso penal consciente de su situación, comprometido con su protección y seguridad y capaz de dar respuesta a unas legítimas expectativas de participación, protección, reparación y asistencia. De esta manera, la victimología proactiva fija entre sus objetivos el de procurar un mejor entendimiento de los intereses de las víctimas, así como medir la reacción del sistema frente a esas expectativas.

PALABRAS-CLAVE: Protección de las víctimas. Proceso Penal Español. Victimología proactiva.

ABSTRACT: The present study analyzes the recent changes in the traditional concept of criminal procedure, considering the trend of an increasing concern with the victim's wellness. Consequently, it is necessary to analyze the quality of the Justice system, in order to confirm whether the criminal process is granting protection, security as well as the minimum conditions to provide answers to the legitimate expectations of participation, protection, reparation and assistance. The proactive victimology stablishes as its objectives

\footnotetext{
${ }^{1}$ Artigo recebido em 14/08/23019, sob dispensa de revisão.

${ }^{2}$ Parte de este trabajo ha sido publicado en Belén Hernández Moura, «El papel de las Oficinas de Asistencia en la satisfacción de los intereses de las víctimas», en Justicia restaurativa: una justicia para las víctimas, Helena Soleto Muñoz y Ana Carrascosa de Miguel (Dirs.), 1. ${ }^{a}$ ed. (Valencia: Tirant lo Blanch, 2019), 521-49.
} 
Revista Eletrônica de Direito Processual - REDP.

Rio de Janeiro. Ano 13. Volume 20. Número 3. Setembro a Dezembro de 2019

Periódico Quadrimestral da Pós-Graduação Stricto Sensu em Direito Processual da UERJ

Patrono: José Carlos Barbosa Moreira (in mem.). ISSN 1982-7636. pp. 51-74

www.redp.uerj.br

the achievement of the victim's interests, as well as measures the system's reaction to those expectations.

KEY WORDS: Victim’s protection. Spanish Criminal Procedure. Proactive victimology.

\section{SUMARIO:}

1.- Introducción. 2.- Propuesta de cambio terminológico: intereses c. necesidades. 3.- Hacia una concreción de los intereses de las víctimas en el marco del proceso penal. 3.1.- Intereses según el momento histórico-procesal. 3.1.1.- Inmediatamente después del hecho delictivo. 3.1.2.- En la fase posterior al hecho delictivo. 3.1.3.- Intereses durante la sustentación del proceso. A-. Acceso a la justicia y participación. B.- Información. C.- Protección, apoyo y asistencia. D.- Reconocimiento y trato respetuoso. E.- Compensación y reparación económica. F.- Sentimiento de legitimidad o justicia. 3.1.4.- Durante la ejecución de la pena. 4.- Confluencias entre el espacio restaurativo y los intereses de la víctima. 5. Algunas consideraciones finales.

\section{1.- Introducción}

En los últimos tiempos estamos asistiendo a un auténtico cambio en la concepción tradicional del proceso penal. El germen del nuevo paradigma se sitúa en Europa, y es que han sido precisamente las instituciones europeas quienes han puesto de manifiesto la situación de las víctimas en el proceso penal, promoviendo una disposición favorable a su reconocimiento y protección. Constituyen buen ejemplo de la orientación victimal en la política criminal europea la Decisión Marco del Consejo, de 15 de marzo de 2001, relativa al estatuto de la víctima en el proceso penal y, particularmente, la Directiva 2012/29/UE, adoptada por el Parlamento y el Consejo el 25 de octubre de 2012 y transpuesta en España a finales de 2015, a través de la Ley 4/2015, de 27 de abril, del Estatuto de la víctima del delito (LEVID en adelante).

Esta sensibilidad en favor de las víctimas exige una reflexión profunda en términos de calidad del sistema de Justicia; exige un proceso penal consciente de su situación, 
Revista Eletrônica de Direito Processual - REDP.

Rio de Janeiro. Ano 13. Volume 20. Número 3. Setembro a Dezembro de 2019

Periódico Quadrimestral da Pós-Graduação Stricto Sensu em Direito Processual da UERJ

Patrono: José Carlos Barbosa Moreira (in mem.). ISSN 1982-7636. pp. 51-74

www.redp.uerj.br

comprometido con su protección y seguridad y capaz de dar respuesta a unas legítimas expectativas de participación, protección, reparación y asistencia.

En la consideración de la vivencia victimal surge la cuestión de si las víctimas tienen necesidades, intereses, expectativas o inquietudes. De entre ellas, algunas o todas tendrán que ser garantizadas o suplidas por el sistema de justicia o el sistema social. Las primeras referencias a la «victimología proactiva» o «victimología de la acción» tienen lugar en la década de los 80, paralelamente al reconocimiento internacional de los derechos de la víctima $^{3}$. A partir de entonces, señala HERRERA MORENO, pasarían a primer plano cuestiones como «la asistencia post-victimización, la promoción judicial de las víctimas y la agilización de soluciones resarcitorias por el ofensor o compensatorias a cargo del Estado» ${ }^{4}$. Para MORILLA FERNÁNDEZ et. al. el debate se centra en «la rehabilitación individual, lo que en su extensión vendría a repercutir en la política e instauración de medidas preventivas y en el proceso concreto de restauración» ${ }^{5}$. La preferencia por la respuesta inmediata a la víctima se traduciría para LANDROVE DÍAZ en la articulación de una «asistencia inaplazable de tipo material, físico o psicológico. Con ello se trata fundamentalmente de estabilizar la situación emocional de las víctimas, impidiendo su traumatización» ${ }^{6}$. Siguiendo a ZARAGOZA AGUADO, con las prioridades así definidas comenzó a trabajarse en la inclusión de «programas concretos de asistencia, auxilio e indemnización a la víctima y programas de protección a la víctima-testigo, fundamentándolos en la idea de solidaridad y en el reconocimiento del fracaso del Estado en la aplicación de los instrumentos diseñados para la tutela del orden social y de la convivencia pacífica» ${ }^{7}$.

De esta manera, durante las últimas décadas y en paralelo al afianzamiento del Estado Social y Democrático de Derecho, la victimología proactiva fija entre sus objetivos el de procurar un mejor entendimiento de los intereses de las víctimas, así como medir la reacción

\footnotetext{
3 Matti Joutsen, The Role of the Victim of Crime in European Criminal Justice Systems: A Crossnational Study of the Role of the Victim (Helsinki: Heuni, 1987); David L. Morillas Fernández, Rosa M. Patró Hernández, y Marta M. Aguilar Cárceles, Victimología: un estudio sobre la víctima y los procesos de victimización (Madrid: Dykinson, 2011), 63-65.

$4 \quad$ Myriam Herrera Moreno, La hora de la víctima: compendio de victimología, vol. 73 (Madrid: Edersa, 1996), 134.

5 David L. Morillas Fernández, Rosa M. Patró Hernández, y Marta M. Aguilar Cárceles, victimología: un estudio sobre la víctima y los procesos de victimización (Madrid: Dykinson, 2011), 317.

6 Gerardo Landrove Díaz, La moderna victimología (Valencia: Tirant lo Blanch, 1998), 91.

7 Javier-Alberto Zaragoza Aguado, «La víctima y su protección asistencial en el Derecho español», en Recurso de amparo, cuestión de inconstitucionalidad y cuestión prejudicial europea. Protección a la víctima. Perspectiva sociológica, asistencial y jurídica., vol. 2, Estudios jurídicos. Ministerio Fiscal. (Madrid: Ministerio de Justicia. Centro de Estudios Jurídicos de la Administración de Justicia, 2000), 297.
} 
Revista Eletrônica de Direito Processual - REDP.

Rio de Janeiro. Ano 13. Volume 20. Número 3. Setembro a Dezembro de 2019

Periódico Quadrimestral da Pós-Graduação Stricto Sensu em Direito Processual da UERJ

Patrono: José Carlos Barbosa Moreira (in mem.). ISSN 1982-7636. pp. 51-74

www.redp.uerj.br

del sistema frente a esas expectativas, cuestión de enorme complejidad debido, como señalara FERREIRO BAAMONDE, a la ausencia de informaciones en este sentido ${ }^{8}$.

Este es uno de los puntos que han sido señalados como insuficientes en la atención a la víctima. Desde el inicio, la doctrina puso de manifiesto como los apenas iniciales estudios cualitativos junto con la orientación eminentemente práctica de la victimología proactiva, repercutieron en el diseño de los programas de apoyo y asistencia; programas que, con HERRERO ALONSO y GARRIDO MARTÍN, asumían casi con carácter universal la realidad de ciertas necesidades a resultas de determinados juicios de valor o, incluso, enfoques políticos. Como indicara ELIAS, no se trata de defender la abstracción de todo planteamiento político en el estudio de la víctima y sus expectativas ${ }^{9}$. Conviene no obstante incidir en el riesgo que supone tomar como necesidades objetivas, lo que, con FERREIRO BAAMONDE, «no son sino interpretaciones de estas u objetivos de política criminal, sustentados en postulados ideológicos [...] que pueden llevar a una utilización simbólica de las víctimas $[\ldots]$ y a olvidar los intereses expresados por ellas, que igualmente dependerán de las perspectivas ideológicas ${ }^{10}$. De esta manera, si el interés se centra prioritariamente en las víctimas de ciertos delitos es evidente el riesgo de definir la realidad, características y expectativas de las víctimas en función de determinados axiomas ideológicos de partida y/o de las metas políticas.

Desde la perspectiva victimológica, si alguna certeza hay en este punto es precisamente lo propio y subjetivo de la vivencia de la victimidad, de la que derivarán después unas u otras expectativas. Coincidimos con DAZA BONACHELA, cuando afirma que «las necesidades de las víctimas de delitos dependen de su situación y de los daños

Xulio Ferreiro Baamonde, La víctima en el proceso penal, $1^{\mathrm{a}}$ (Madrid: La Ley, 2005), 96-97.

Elias reflexiona sobre la idoneidad de proveer una base ideológica a la victimología en pro de una incidencia real en la situación real de las víctimas. Para el autor « [...] In other words, politics is inevitable. Trying to be neutral in our research does not negate the political uses to which it will be put. To the contrary, only by not being neutral will we avoid having our research being used inappropriately. [...] Not only is our research susceptible to political uses, and not only do we at least implicitly make political choices when we conduct research, but we should be making those choices. Why do science if it has no humanism, if it makes no contribution to human development? How can we be neutral about how to best use our science in society? Those decisions are all a matter of politics and ideology». Vid. Robert Elias, «Paradigms and Paradoxes of Victimology», en International Victimology: Selected Papers from the 8th International Symposium. AIC conference proceedings, ed. Chris Sumer et al. (Canberra: Australian Institute of Criminology, 1996), 13 y ss., https://aic.gov.au/publications/proceedings/27.

10 Ferreiro Baamonde, La víctima en el proceso penal, 98. 
Revista Eletrônica de Direito Processual - REDP.

Rio de Janeiro. Ano 13. Volume 20. Número 3. Setembro a Dezembro de 2019

Periódico Quadrimestral da Pós-Graduação Stricto Sensu em Direito Processual da UERJ

Patrono: José Carlos Barbosa Moreira (in mem.). ISSN 1982-7636. pp. 51-74

www.redp.uerj.br

concretos que sufran a consecuencia de la victimización» ${ }^{11}$. En línea con esta hipótesis y según el modelo de LAZARUS y FOLKMAN, la reacción de la víctima obedece así a una serie de parámetros objetivos vinculados con sucesos estresantes externos -intensidad, duración y acontecimientos de vida estresantes — y con la estimación subjetiva de la víctima sobre los recursos psicológicos — propios y exteriores - disponibles para afrontar los sucesos estresantes ${ }^{12}$.

\section{2.- Propuesta de cambio terminológico: intereses c. necesidades}

Cuando la doctrina se ha referido a esta cuestión, lo ha hecho habitualmente refiriéndose a las necesidades de las víctimas. Prácticamente, se mantiene unánime el uso del concepto necesidad; sin embargo, en obras más recientes y en algunas de las regulaciones internacionales se observa un uso cada vez más frecuente del término interés. Desde el ámbito anglosajón, DALY reflexiona sobre la idoneidad de emplear dicha terminología y aboga por un cambio de enfoque que exigiría también una variación terminológica ${ }^{13}$. Desde nuestro punto de vista, parece más adecuado sustituir el término de necesidades por el de intereses, concepto además familiar en el ámbito de la gestión de conflictos. URY et. al. distinguen tres métodos entre los tradicionales en la gestión de conflictos — poder, derecho e intereses-, siendo la última la forma más evolucionada de gestión, propia de sociedades democráticamente avanzadas ${ }^{14}$. Asimismo, desde la teoría de la negociación, FISHER y URY hablan de intereses para referirse a las verdaderas motivaciones de las partes ${ }^{15}$.

De otro lado, BENNETT advierte el riesgo de un enfoque que asuma siempre y en todo caso que el sistema debe responder a las expectativas de la víctima o a sus intereses expresados o no-; cuestión distinta es que efectivamente se proporcione un espacio para

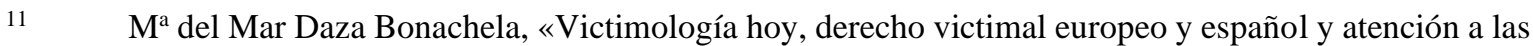
víctimas de delitos en España» (Universidad de Granada. Departamento de Derecho Penal., 2014), 146, digibug.ugr.es/bitstream/10481/34696/1/24310402.pdf.

12 Lazarus S. Lazarus y Susan Folkman, Stress, Appraisal and Coping (Nueva York: Springer Publishing Company, Inc, 1984).

13 Kathleen Daly, «Sexual violence and victims’ justice interests», en Restorative Responses to Sexual Violence. Legal, Social and Therapeutic Dimensions, de Estelle Zinsstag y Marie Keenan, 1. ${ }^{\text {ed }}$. (Great Britain: Routledge, 2017), 114.

14 William Ury, Jeanne M. Brett, y Stephen B. Goldberg, Getting Disputes Resolved. Designing Systems to Cut the Cost of Conflict, 1. a ed. (San Francisco: Jossey-Bass Inc. Publishers, 1988), 3-19.

15 Roger Fisher y William Ury, Getting to Yes: Negotiating Agreement without Giving In, $1 .^{\mathrm{a}} \mathrm{ed}$. (New York: Penguin, 1981).
} 
Revista Eletrônica de Direito Processual - REDP.

Rio de Janeiro. Ano 13. Volume 20. Número 3. Setembro a Dezembro de 2019

Periódico Quadrimestral da Pós-Graduação Stricto Sensu em Direito Processual da UERJ

Patrono: José Carlos Barbosa Moreira (in mem.). ISSN 1982-7636. pp. 51-74

www.redp.uerj.br

que la víctima pueda compartir su visión y expresar sus intereses ${ }^{16}$. Así, el autor prefiere

hablar de las expectativas que las víctimas pueden razonablemente mantener respecto del victimario y respecto del Estado o, desde otra perspectiva, de que obligaciones y/o compromisos mantienen tanto el ofensor como el Estado respecto de la víctima. Como indica SOLETO MUÑOZ, las expectativas de justicia van variando en intensidad, de manera que «el ciudadano de los países desarrollados y en vías de desarrollo tienen unas expectativas en relación con la justicia mucho más amplias y exigentes que las existentes en la segunda mitad del siglo $X X{ }^{17}$; ya no se reclama únicamente que la Justicia sea «justa y transparente, sino que eleve sus exigencias de calidad. El ciudadano contemporáneo espera principalmente que la Justicia sea rápida, con un coste adecuado y de eficaz cumplimiento» ${ }^{18}$.

Junto con las más habituales de tipo estructural —independencia judicial, inversión, medios materiales y personales, tiempos de pendencia, etc. - , entre las variables que sirven para medir la calidad alcanzada en el sistema de justicia, pueden incluirse otros indicadores relacionados con la experiencia del usuario del sistema de justicia. En una perspectiva relacional y política, HOLDER argumenta a favor de este cambio en la terminología refiriéndose a los derechos de la víctima como ciudadano y a su interés en la realización de justicia, desde el punto de vista individual, pero también en relación con el victimario y la sociedad $^{19}$.

\section{3.- Concreción de los intereses de las víctimas en el marco del proceso penal}

Los intereses de las víctimas variarán no solo en función del delito sufrido, también en base a las características individuales de la víctima y de cuál haya sido la vivencia de victimidad. Consecuentemente, incluso en el marco del proceso penal, los intereses de las víctimas podrán explicarse desde estándares muy diferentes. Las expectativas de las víctimas van a partir de una determinada base cultural, estarán relacionadas con las expectativas de

\footnotetext{
16 Bennet Christopher, «Satisfying the Needs and Interests of Victims», en Handbook of Restorative Justice, de Johnstone Gerry y Van Ness Daniel W. (Devon: Willan Publishing, 2007), 248.

17 Helena Soleto Muñoz, «La conferencia Pound y la adecuación del método de resolución de conflictos», Revista de Mediación 10, n. ${ }^{\circ}$ (2017): 4, https://revistademediacion.com/articulos/la-conferencia-pound-laadecuacion-del-metodo-resolucion-conflictos/.

18 Soleto Muñoz, 4.

19 Robyn L. Holder, «Just Interest: Victims, Citizens and the Potential for Justice» (Australia National University, $\quad 2013$ ), $\quad 67 \quad$ y $\quad$ ss., $\quad$ https://openresearchrepository.anu.edu.au/bitstream/1885/.../1/Holder_R.L._2013L.pdf.
} 
Revista Eletrônica de Direito Processual - REDP.

Rio de Janeiro. Ano 13. Volume 20. Número 3. Setembro a Dezembro de 2019

Periódico Quadrimestral da Pós-Graduação Stricto Sensu em Direito Processual da UERJ

Patrono: José Carlos Barbosa Moreira (in mem.). ISSN 1982-7636. pp. 51-74

www.redp.uerj.br

reparación que se mantengan e, incluso, vendrán marcadas en función del conocimiento respecto a los recursos y posibilidades existentes ${ }^{20}$.

Los intereses que se han señalado de manera más recurrente son aquellos relacionados con la participación en el proceso, apoyo emocional, disponibilidad de espacios de escucha, seguridad personal de la víctima, información sobre el progreso de la causa, asesoramiento, asistencia en el ámbito financiero y la reparación del daño, incluida la orientación sobre el modo de pretender una eventual indemnización o reclamaciones a compañías aseguradoras $^{21}$. También se identifican otro tipo de intereses: garantía de no repetición, reconocimiento de los hechos y del agresor como culpable, evitación de la confrontación visual con el victimario, necesidad de atención y protección, sentimiento de cierre o toma de conciencia por parte del victimario ${ }^{22}$.

La experiencia muestra, con DAZA BONACHELA, que los intereses esenciales de las víctimas son «saberse a salvo, de seguridad y, en caso necesario, protección para evitar que continúe la victimización [...], y por otra, [...] de reconocimiento, necesidad humana básica, que requiere la posibilidad de expresarse y ser escuchadas, y de comprender, y que se comprendan, las razones de su victimización» ${ }^{23}$. Asimismo, continua la autora, «es básica la necesidad de reparación — de la que el reconocimiento es presupuesto-, ya sea real, mediante la indemnización del daño, o incluso simbólica cuando la indemnización no sea posible. La única necesidad victimal tradicionalmente contemplada por el Derecho Penal ha sido [...] la de restitución, reparación o resarcimiento civil, pero normalmente resulta obstaculizada en su aplicación por la saturación de la Administración de Justicia y por la insolvencia o maniobras en orden a su simulación por los obligados al pago» ${ }^{24}$.

Otras consideraciones importantes, derivadas de las expectativas de reconocimiento y reparación, son las de información, participación y asistencia, para cuya efectiva realización las Oficinas de Asistencia a las Víctimas (OAVs en adelante) se postulan como un factor clave en la satisfacción de las víctimas. WALLER distingue además un tercer grupo de medidas que el autor denomina «de buen gobierno» y entre las que incluye la necesidad de

\footnotetext{
$20 \quad$ Mike Maguire, «The Needs and Rights of Victims of Crime», Crime and justice 14 (1991): 404.

$21 \quad$ Maguire, 404-5; Leeana A. Bouffard et al., «Service Providers’ Knowledge and Perceptions of the Legal Service Needs of Crime Victims», American Journal of Criminal Justice 42, n. ${ }^{\circ} 3$ (2017): 589-609.

22 Vid. Annemarie ten Boom y Karlijn F. Kuijpers, «Victims’ Needs as Basic Human Needs», International Review of Victimology 18, n. ${ }^{\circ}$ (2012): 155-79.

23 Daza Bonachela, «Victimología hoy, derecho victimal europeo y español y atención a las víctimas de delitos en España», 147.

24 Daza Bonachela, 147-48.
} 
Revista Eletrônica de Direito Processual - REDP.

Rio de Janeiro. Ano 13. Volume 20. Número 3. Setembro a Dezembro de 2019

Periódico Quadrimestral da Pós-Graduação Stricto Sensu em Direito Processual da UERJ

Patrono: José Carlos Barbosa Moreira (in mem.). ISSN 1982-7636. pp. 51-74

www.redp.uerj.br

mejores políticas para disminuir la victimización y el establecimiento de medidas que eviten la simple declaración de intenciones ${ }^{25}$.

\section{1.- Intereses según el momento histórico-procesal}

\subsection{1.- Inmediatamente después del hecho delictivo}

En esta etapa, será conveniente producir o reforzar el sentimiento de seguridad de las víctimas, proporcionar ayuda médica urgente si corresponde y procurar que las víctimas perciban el esfuerzo por parte de las autoridades en la prevención de posibles daños futuros. El cómo se organice la asistencia de emergencia será después una cuestión clave para la víctima del delito. Esta primera ayuda, de carácter perentorio, estará fuertemente influida por el esquema piramidal de MASLOW y vendrá determinada por la protección y seguridad de los supervivientes, auxilio sanitario y prevención de daños inmediatos ${ }^{26}$. En este momento la orientación psicológica puede concretarse en un acompañamiento que favorezca un mejor control de la angustia, el estrés o nerviosismo inicial. La ayuda así entendida puede ser positiva para controlar el sentimiento de desconfianza, recelo, rencor o miedo que puede estar experimentando la víctima directa. No obstante, en tanto el auxilio se dirija a comprender y dimensionar estas reacciones e impedir el establecimiento del trauma, también para la víctima indirecta puede representar un beneficio.

Ahora bien, siguiendo a PEMBERTON, esta primera actuación no es necesariamente una intervención terapéutica, tampoco de tipo preventivo; se trataría más bien de ofrecer a la víctima información en torno a las reacciones psicológicas más frecuentes, concienciar sobre la importancia del seguimiento psicológico posterior e informar acerca de los servicios disponibles $^{27}$. En esta línea, ECHEBURÚA y DE CORRAL, se refieren al debriefing psicológico $^{28}$ como una «breve intervención inmediata que se ofrece a las personas que han

25 Irvin Waller, Rebalancing Justice. Rights for victims of crime, 1.a ed. (Rowman \& Littlefield Publishers, 2011), 28 y ss.

26 Abraham H. Maslow, Motivación y personalidad, trad. Claridad Clemente (Madrid: Ediciones Díaz de Santos, 1991), 21 y ss.

27 Antony Pemberton, Rianne Letschert, e Ines Staiger, Assisting Victims of Terrorism: Towards a European Standard of Justice, 1. Aufl. (Springer Netherlands, 2010), 76.

28 Herrera Moreno se refiere al debriefing como «un haz de recursos terapéuticos populares, pero abiertamente cuestionados, más allá de la estabilidad y regularidad de su aplicación en el ámbito de asistencia a víctimas de extrema y violenta victimización». Al hilo de las alusiones a la mercantilización y medicalización propias de la victimología crítica la autora repasa algunos de los motivos por los que se cuestiona la 
Revista Eletrônica de Direito Processual - REDP.

Rio de Janeiro. Ano 13. Volume 20. Número 3. Setembro a Dezembro de 2019

Periódico Quadrimestral da Pós-Graduação Stricto Sensu em Direito Processual da UERJ

Patrono: José Carlos Barbosa Moreira (in mem.). ISSN 1982-7636. pp. 51-74

www.redp.uerj.br

estado expuestas a un acontecimiento traumático, habitualmente en el mismo lugar de los hechos, y que tiene como objetivo prevenir alteraciones psicopatológicas posteriores, especialmente el estrés postraumático» ${ }^{29}$. Para los autores, el rasgo esencial de este tipo de intervención es que se desarrolla en un contexto grupal de personas que han enfrentado el mismo suceso y su objetivo es el de resolver, o, en palabras de los autores, «ventilar las emociones de las víctimas y analizar sus pensamientos, sentimientos y conductas con un profesional formado, que, a su vez, ofrece psicoeducación sobre las respuestas normales a un suceso traumático y hace ver el carácter no patológico de estas reacciones en una situación crítica anormal» ${ }^{30}$. Consiste, al fin y al cabo, en favorecer un procesamiento emocional conveniente del trauma, así como de recomendar determinadas habilidades o estrategias de enfrentamiento para encarar dicha situación de estrés, empleando el soporte del grupo.

\subsection{2.- En la fase posterior al hecho delictivo}

Entre las expectativas que pueden surgir tras la experiencia victimal se encuentran las de tipo práctico y económico, tanto en el momento inmediatamente posterior a la comisión del hecho delictivo, como en lo que se refiere a una estabilidad económica a medio y largo plazo. Esta ayuda económica englobaría las cuestiones más apremiantes, destinadas a reparaciones materiales urgentes o relacionadas con el ámbito de la vivienda, facilidades en el pago de tasas académicas, o, entre otras, participación en programas de formación y orientación laboral. Especial incidencia tendrá en este ámbito la agilización, asesoramiento y asistencia en lo relativo al trámite de asistencia jurídica a víctimas ${ }^{31}$.

\subsection{3.- Intereses durante la sustentación del proceso}

Siguiendo la clasificación realizada por PEMBERTON, las necesidades relacionadas con el proceso pueden dividirse en tres grandes categorías: tratamiento justo y respetuoso,

\footnotetext{
intervención. Vid. Myriam Herrera Moreno, «Sobre víctimas y victimidad. Aspectos de controversia científica en torno a la condición de víctima», en Víctima, prevención del delito y tratamiento del delincuente, de Antonio García-Pablos de Molina, 1a , vol. 105, Estudios de Derecho Penal y Criminología (Granada: Comares, 2009), 89-91.

29 Enrique Echeburúa y Paz De Corral, «Intervención en crisis en víctimas de sucesos traumáticos: ¿cuándo, cómo y para qué?», Psicología Conductual 15, n.o 3 (2007): 380.

30 Echeburúa y De Corral, 380.

31 Vid. Tamara Martínez Soto, «Justicia restaurativa y terrorismo: la reparación de las víctimas del terrorismo en España» (Universidad Carlos III de Madrid, 2016), 189, http://hdl.handle.net/10016/22564.
} 
Revista Eletrônica de Direito Processual - REDP.

Rio de Janeiro. Ano 13. Volume 20. Número 3. Setembro a Dezembro de 2019

Periódico Quadrimestral da Pós-Graduação Stricto Sensu em Direito Processual da UERJ

Patrono: José Carlos Barbosa Moreira (in mem.). ISSN 1982-7636. pp. 51-74

www.redp.uerj.br

información relacionada con la marcha del proceso y los resultados del mismo y posibilidad de participación en la causa ${ }^{32}$. Ahora bien, dentro de la más global de sentimiento y trato respetuoso pueden distinguirse necesidades de otro tipo, más concretas, —participación, protección, apoyo, asistencia y compensación-.

\section{A-. Acceso a la justicia y participación}

Destacamos el interés de participación en el proceso penal, participación que contribuiría a recuperar la capacidad de control perdida tras la comisión del hecho delictivo y a salvar el desequilibrio a resultas de él. Por su parte, STRANG subraya la necesidad de participar en procesos menos formales, la necesidad de reparación y compensación, de ayuda o soporte social y comunitario y la necesidad de recibir una disculpa por parte del victimario $^{33}$. Para BOLÍVAR, «la información que se pueda recibir sobre el caso ayuda, además de promover también una mayor sensación de control, a entender lo sucedido y, por lo tanto, a encontrar un significado a lo vivido. [...] La víctima busca encontrar datos, pedazos de información que pudieran ayudar a explicar lo sucedido. El por qué yo es otra pregunta repetitiva. La oportunidad de encontrar al ofensor y preguntárselo directamente se transforma en una oportunidad única para entender algo que hasta el momento no pudo ser entendido» ${ }^{34}$.

Siguiendo a DALY, el interés de participación en el marco del proceso tendría un contenido más amplio, de manera que, en el interés de participación de las víctimas, se entenderían incluidas las expectativas de información respecto a las diferentes opciones procesales y extraprocesales disponibles, así como en relación al desarrollo del proceso, la posibilidad de realizar preguntas y obtener datos o informaciones sobre las circunstancias del delito. Si esa participación se define en el marco de los mecanismos informales de justicia, habría además que añadir la posibilidad participar de forma activa en el diseño de la reparación ${ }^{35}$.

\footnotetext{
32 Pemberton, Letschert, y Staiger, Assisting Victims of Terrorism: Towards a European Standard of Justice, 77 y ss.

33 Heather Strang, Repair or Revenge: Victims and Restorative Justice (Clarendon Press, 2004).

34 Daniela Bolívar, «La víctima en la Justicia restaurativa: reflexiones desde una perspectiva psico-social», en Jornadas de Justicia Restaurativa, de Inés Olaizola Nogales y Paz Francés Lecumberri (Navarra: Ediciones Universidad Pública de Navarra, 2011).

35 Daly, «Sexual violence and victims’ justice interests», 115-16.
} 
Revista Eletrônica de Direito Processual - REDP.

Rio de Janeiro. Ano 13. Volume 20. Número 3. Setembro a Dezembro de 2019

Periódico Quadrimestral da Pós-Graduação Stricto Sensu em Direito Processual da UERJ

Patrono: José Carlos Barbosa Moreira (in mem.). ISSN 1982-7636. pp. 51-74 www.redp.uerj.br

No podemos dejar de señalar que la reclamación o demanda de justicia no debería ser identificada con un deseo de sufrimiento hacia el victimario. La individualidad de los intereses es tal que no deben entenderse como prioritarios siempre y en todo caso los de tipo económico o vindicativo ${ }^{36}$. Por el contrario, esa demanda abarcaría un espectro más amplio en el que caben igualmente, otros factores de estabilización como el reconocimiento o la reparación del sentimiento de seguridad. En este sentido, la Administración de Justicia deberá articular todos los mecanismos disponibles para asegurar la participación activa de la víctima, a través, por ejemplo, de la oportuna representación jurídica, facilitando la intelección de la información que se proporcione y el alcance de cada una de las actuaciones que puedan tener algún tipo de influencia en la defensa de sus intereses.

\section{B.- Información}

Existe cierto consenso entre la doctrina en señalar la necesidad de información como una de las más relevantes para la víctima. En efecto, en los momentos iniciales de la investigación o durante las primeras diligencias, uno de los aspectos que definirán la experiencia de la víctima con el sistema de justicia es precisamente la aptitud para asegurar a la víctima el acceso y comprensión de la información, incluyendo información sobre los derechos que le asisten y su forma de realización. Y lo es porque, como indica LEAL MEDINA, «el derecho a la información [...] se configura como un presupuesto imprescindible para su posterior ejercicio» ${ }^{37}$.

La información solo será realmente útil cuando la persona victimizada sea capaz de comprenderla en todo su alcance y extensión. Para ello, lo esencial es que se proporcione de acuerdo a las características de la víctima, de manera accesible y adecuada. Desde el punto de vista legislativo se han previsto medidas dirigidas a apoyar a las víctimas en la comprensión de dicha información a través, entre otros, de la configuración de diferentes servicios de traducción e interpretación, así como mediante el establecimiento de servicios de asesoramiento.

\footnotetext{
36 Sobre el rol vindicativo y la hipotética necesidad de venganza vid. ampliamente Bas van Stokkom, «Victims' Needs and Participation in Justice: Is There a Role for Vengeance?», Restorative Justice: An International Journal 1, n. ${ }^{\circ} 2$ (2013): 175 y ss., https://doi.org/10.5235/20504721.1.2.168.

37 Julio Leal Medina, «Régimen jurídico de la víctima del delito. Normativa presente y de futuro. Derechos en el proceso penal y en las leyes extraprocesales. Especial atención al Anteproyecto de la Ley Orgánica del Estatuto de la víctima del delito.», Diario La Ley 8287 (7 de abril de 2014): 3.
} 
Revista Eletrônica de Direito Processual - REDP.

Rio de Janeiro. Ano 13. Volume 20. Número 3. Setembro a Dezembro de 2019

Periódico Quadrimestral da Pós-Graduação Stricto Sensu em Direito Processual da UERJ

Patrono: José Carlos Barbosa Moreira (in mem.). ISSN 1982-7636. pp. 51-74

www.redp.uerj.br

El interés en el acceso a la información puede relacionarse con el interés de alcanzar

la verdad material a través del proceso. Comprender las razones de la victimización adquiere gran significancia en los modelos cognitivos de estrés postraumático, según los cuales el pensamiento obsesivo y recurrente sobre lo sucedido puede ralentizar la reflexión sobre la capacidad para contraponerse al hecho delictivo. Este interés se traduce en el derecho a disponer por escrito del lugar y del día de celebración del juicio y la notificación de la sentencia, sin que para ello la víctima haya tenido que personarse previamente en la causa. Esta información puede conectarse también con el deseo de entender qué ocurrió y por qué fueron ellas las destinatarias de la acción, lo que a su vez permitiría a las víctimas otorgar, dotar de sentido a su experiencia victimal. Además, resultaría positivo para las víctimas recibir algún tipo de preparación u apoyo de cara al juicio, de manera que pudiesen afrontar los interrogatorios conociendo la dinámica en la que tendrán lugar. Cuestión especialmente delicada, en tanto, indica ORTH, son probables las interferencias con el principio de presunción de inocencia que podría ser percibido por las víctimas como un desequilibrio en la consideración de sus intereses. En este sentido, cuestionar la culpa del perpetrador implicaría paralelamente cuestionar la credibilidad del testimonio de la víctima ${ }^{38}$.

Las víctimas valorarán de forma positiva una actitud atenta y un tono afable durante las sesiones, con un tiempo adecuado para responder y que se les informe previamente del alcance de la declaración. Sin embargo, la realidad forense no siempre coincide con lo que sería deseable. En la práctica, la táctica de la defensa suele centrarse en cuestionar la credibilidad del testigo, de la víctima-testigo, estrategia con una intensa repercusión en términos de justicia interaccional ${ }^{39}$. En este sentido, son frecuentes los ejemplos de intervenciones poco sensibles a la intimidad de la víctima u observaciones que sugieren una degradación o minimización del daño, muy especialmente en el caso de violencias sexuales.

\section{C.- Protección, apoyo y asistencia}

Las expectativas de seguridad y protección estarán presentes durante toda la vida del proceso, hasta la eventual y durante la fase de ejecución. De este modo, la protección será

\footnotetext{
38 Uli Orth, «Secondary Victimization of Crime Victims by Criminal Proceedings», Social Justice Research 15, n. 4 (2002): 316.

39 Melissa Schaefer Morabito, April Pattavina, y Linda M. Williams, «It All Just Piles Up: Challenges to Victim Credibility Accumulate to Influence Sexual Assault Case Processing», Journal of Interpersonal Violence, 2016, 1-20, https://doi.org/DOI: 10.1177/0886260516669164.
} 
Revista Eletrônica de Direito Processual - REDP.

Rio de Janeiro. Ano 13. Volume 20. Número 3. Setembro a Dezembro de 2019

Periódico Quadrimestral da Pós-Graduação Stricto Sensu em Direito Processual da UERJ

Patrono: José Carlos Barbosa Moreira (in mem.). ISSN 1982-7636. pp. 51-74

www.redp.uerj.br

una cuestión decisiva más allá del momento de presentación de la denuncia, con plena influencia en la toma de decisiones procesales de la víctima. En buena parte de los casos, la víctima será además testigo del hecho y por ello precisa ser protegida de posibles represalias u otros comportamientos conminatorios por parte del victimario. La víctima, en definitiva, debe sentirse protegida frente al riesgo de sufrir nuevas o dobles victimizaciones, máxime si participa en las investigaciones y procedimientos judiciales, previniendo un trato inapropiado o poco sensible a sus intereses.

En el interés de protección puede distinguirse una doble vertiente: seguridad personal de la víctima y sus allegados frente a hipotéticas nuevas victimizaciones $\mathrm{y}$, de otro lado, protección de la víctima frente a la victimización secundaria. En esta segunda categoría, habrá que prestar especial atención a la adecuación de las dependencias policiales y judiciales y la no confrontación visual, la protección de la intimidad de la víctima durante la investigación y las propias sesiones del juicio o, entre otras cuestiones, la evitación de comparecencias y/o reconocimientos innecesarios. Estos perjuicios han sido ampliamente descritos por la doctrina refiriéndose a ellos como «segunda victimización», «victimización institucional» $\mathrm{o}$ «victimización secundaria» ${ }^{40}$; así, LORENTE y MORENO sitúan el origen de la victimización secundaria «en la colisión que se produce entre dicho sistema, las legítimas expectativas de la persona víctima y la realidad institucional» ${ }^{41}$.

El apoyo a la víctima se concreta en la asistencia de los servicios de emergencia y de profesionales en la prestación de unos primeros auxilios psicológicos. La necesidad de apoyo seguirá además vigente durante toda la sustentación del proceso, apoyo que puede ser de índole jurídico, emocional o práctico para mantenerse regularmente informada sobre el progreso de las actuaciones, cuestión, como se ha visto, primaria para las víctimas. Sería conveniente facilitar esa protección terapéutica frente a posibles reacciones culpabilizantes en el entorno de la víctima, siendo la ausencia de apoyo social una de las causas con más incidencia en la no superación del delito.

\footnotetext{
40 Enrique Echeburúa Odriozola y Paz De Corral, «Especial consideración de algunos ámbitos de victimación», en Manual de Victimología, ed. Enrique Baldomero Baca Baldomero, Enrique Echeburúa Odriozola, y Josep María Tamarit Sumalla (Valencia: Librería Tirant lo Blanch, 2006), 157.

$41 \quad$ Lourdes Lorente y Roberto Moreno, «El servicio de atención a la víctima (SAV) como elemento fundamental del sistema de justicia restaurativa del Gobierno Vasco», en Victimología: en busca de un enfoque integrador para repensar la intervención con víctimas, de Gema Varona Martínez, $1^{\text {a }}$ (Navarra: Thomson Reuters-Aranzadi, 2018), 170.
} 
D.- Reconocimiento y trato respetuoso

Siguiendo a COBB, «en el campo de la resolución de conflictos, existe una creencia generalizada de que la ausencia de reconocimiento es, a la vez, síntoma y causa del conflicto» ${ }^{42}$. Es clara la conveniencia de procurar un reconocimiento y trato profesional respetuoso e individualizado en todas las comunicaciones con el personal que, en cualquier forma, participe en la tramitación de los procesos, estudiando de manera personalizada los daños padecidos. En este sentido, será imprescindible garantizar una especial observación respecto de las víctimas más vulnerables, menores de edad, personas discapacitadas, víctimas de violencias sexuales o del terrorismo. Este trato respetuoso alcanza igualmente a las víctimas indirectas, familiares u otras personas dependientes de las víctimas directas, afectadas también por el delito.

\section{E.- Compensación y reparación económica}

Una de las cuestiones esenciales para la víctima es la garantía de una reparación adecuada. Esta compensación no debería limitarse a los daños financieros inmediatos, al margen de que sea ésta una de las cuestiones de máxima preocupación para las víctimas, especialmente si se han producido daños físicos o materiales que pongan en peligro la satisfacción de sus necesidades básicas. En esta compensación debieran incluirse también los daños más a largo plazo, como posibles gastos médicos, pérdidas en la producción u otros activos intangibles.

Además de cubrir las necesidades financieras directas de las víctimas, la compensación puede servir a otras cuestiones conectadas con lo simbólico. Así, la indemnización puede explicarse también como fuente del reconocimiento de lo injusto del hecho, de los daños producidos y de la condición de víctima. De otro lado, el acceso a los servicios de Justicia restaurativa, como un espacio complementario al sistema tradicional, permitiría explorar diferentes posibilidades de reparación, económica, pero también emocional.

42 Sara Cobb, Hablando de violencia. La política y las poéticas narrativas en la resolución de conflictos, trad. María Natalia Prunes y Cecilia Sobrón, 1. ${ }^{\text {a }}$ ed. (Barcelona: Gedisa editorial, 2016), 59. 
F.- Sentimiento de legitimidad o justicia

La experiencia de justicia implicaría la confirmación de que el hecho fue efectivamente injusto y contrario al ordenamiento jurídico, y que, por ello, sería necesario impulsar acciones dirigidas a la recomposición de la situación anterior. Desde este punto de vista, la necesidad de justicia puede relacionarse con la necesidad de ser escuchado, tratado con respeto, reconocido o validado en sus emociones. El trabajo de DEVALVE muestra como un $47,22 \%$ de la muestra de referencia, al ser preguntada sobre la importancia de comprender el porqué de la experiencia victimal, lo calificó como muy importante. Igualmente llamativo es que el 55,5\% mostró interés en explicar al victimario las implicaciones de la victimización ${ }^{43}$.

El cuestionamiento del modelo punitivo ha favorecido la aparición de propuestas alternativas incardinadas en una corriente más amplia que la doctrina ha denominado Comprehensive Law dentro del cual podrían incluirse, además de la Justicia procedimental, la Justicia terapéutica y la Justicia restaurativa, a la que más adelante aludiremos ${ }^{44}$. En términos de justicia procedimental y victimológica, el propósito de un sistema de Justicia no es otro que el de constituir garantías jurídicas y buenas prácticas en el seno del proceso que posibiliten, de un lado, que las víctimas perciban que en efecto son tratadas de un modo justo y deferente $\mathrm{y}$, de otro lado, que propicie y garantice que pueden estar informadas, ser escuchadas y participar en términos de garantías. Solo así podrá prevenirse el sentimiento de desvalimiento, abandono, confusión y pérdida de control sobre una cuestión que de lleno les afecta.

\subsection{4.- Durante la ejecución de la pena}

En esta etapa los intereses no difieren demasiado de los expuestos hasta ahora; podría decirse incluso que las expectativas en esta fase no son más que diferentes concreciones de los intereses de información y seguridad arriba expuestos. Las víctimas estimarían positivamente, no solo el hecho de ser informadas de determinados hitos relevantes en el

\footnotetext{
43 Elizabeth Quinn DeValve, «A Qualitative Exploration of the Effects of Crime Victimization for Victims of Personal Crime», Applied Psychology in Criminal Justice 1, n.o 2 (2005): 82.

44 Esther Pillado González, «La justicia terapéutica y sus manifestaciones en el proceso penal español», en Mediación, arbitraje y jurisdicción en el actual paradigma de justicia, de Silvia Barona Vilar, $1 .^{a}$ ed. (Navarra: Thomson Reuters-Civitas, 2016), 251-76.
} 
Revista Eletrônica de Direito Processual - REDP.

Rio de Janeiro. Ano 13. Volume 20. Número 3. Setembro a Dezembro de 2019

Periódico Quadrimestral da Pós-Graduação Stricto Sensu em Direito Processual da UERJ

Patrono: José Carlos Barbosa Moreira (in mem.). ISSN 1982-7636. pp. 51-74

www.redp.uerj.br

cumplimiento de la pena, sino también ser consultadas en torno a las condiciones en las que se materializa el derecho a la información. Igualmente, y ya en conexión con la necesidad de participación, las víctimas valorarían adecuadamente la posibilidad de ofrecer información relevante en la decisión sobre la suspensión de la ejecución de la pena o a la hora de supeditar dicha suspensión a la realización de las algunas de las condiciones de orientación victimal que se recogen en el art. $83 \mathrm{CP}_{\text {español }}{ }^{45}$.

\section{Confluencias entre el espacio restaurativo y los intereses de la víctima}

La pérdida de confianza en los sistemas de justicia y el desarrollo de los métodos alternativos no es un fenómeno desconocido en el orden penal. Las nuevas metodologías aplicadas a la justicia penal junto con el auge de la victimología, han favorecido un auténtico cambio de paradigma ${ }^{46}$ no solo en la comprensión y tratamiento del hecho delictivo, también en la explicación de la función de la pena o en el papel de la víctima en la gestión del conflicto.

La Justicia restaurativa — JR en adelante — introduce un nuevo giro en las estructuras clásicas del sistema penal a través de la revisión de las respuestas disponibles frente al delito.

$45 \quad$ Según el literal del art. $83 \mathrm{CP}$, « El juez o tribunal podrá condicionar la suspensión al cumplimiento de las siguientes prohibiciones y deberes cuando ello resulte necesario para evitar el peligro de comisión de nuevos delitos, sin que puedan imponerse deberes y obligaciones que resulten excesivos y desproporcionados: 1. ${ }^{a}$ Prohibición de aproximarse a la víctima o a aquéllos de sus familiares u otras personas que se determine por el juez o tribunal, a sus domicilios, a sus lugares de trabajo o a otros lugares habitualmente frecuentados por ellos, o de comunicar con los mismos por cualquier medio. [...]. 2. ${ }^{\text {a }}$ Prohibición de establecer contacto con personas determinadas o con miembros de un grupo determinado, cuando existan indicios que permitan suponer fundadamente que tales sujetos pueden facilitarle la ocasión para cometer nuevos delitos o incitarle a hacerlo. 3. ${ }^{a}$ Mantener su lugar de residencia en un lugar determinado con prohibición de abandonarlo o ausentarse temporalmente sin autorización del juez o tribunal. 4. ${ }^{a}$ Prohibición de residir en un lugar determinado o de acudir al mismo, cuando en ellos pueda encontrar la ocasión o motivo para cometer nuevos delitos. 5. ${ }^{\text {a }}$ Comparecer personalmente con la periodicidad que se determine ante el juez o tribunal, dependencias policiales o servicio de la administración que se determine, para informar de sus actividades y justificarlas. 6. ${ }^{a}$ Participar en programas formativos, laborales, culturales, de educación vial, sexual, de defensa del medio ambiente, de protección de los animales, de igualdad de trato y no discriminación, y otros similares. 7. ${ }^{a}$ Participar en programas de deshabituación al consumo de alcohol, drogas tóxicas o sustancias estupefacientes, o de tratamiento de otros comportamientos adictivos. 8. ${ }^{a}$ Prohibición de conducir vehículos de motor que no dispongan de dispositivos tecnológicos que condicionen su encendido o funcionamiento a la comprobación previa de las condiciones físicas del conductor, cuando el sujeto haya sido condenado por un delito contra la seguridad vial y la medida resulte necesaria para prevenir la posible comisión de nuevos delitos.

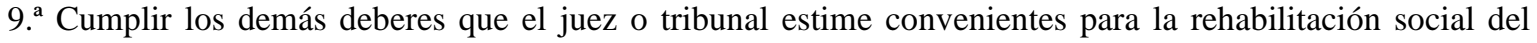
penado, previa conformidad de éste, siempre que no atenten contra su dignidad como persona».

46 José-Pascual Ortuño Muñoz y Javier Hernández García, Sistemas alternativos a la resolución de conflictos (ADR): la mediación en las jurisdicciones civil y penal (Fundación alternativas, 2007), 59 y ss.; Margarita Martínez Escamilla, «Justicia restauradora, mediación y sistema penal: diferentes estrategias, ¿los mismos objetivos?», en Estudios penales en homenaje a Enrique Gimbernat, ed. Carlos García Valdés 
Revista Eletrônica de Direito Processual - REDP.

Rio de Janeiro. Ano 13. Volume 20. Número 3. Setembro a Dezembro de 2019

Periódico Quadrimestral da Pós-Graduação Stricto Sensu em Direito Processual da UERJ

Patrono: José Carlos Barbosa Moreira (in mem.). ISSN 1982-7636. pp. 51-74

www.redp.uerj.br

En palabras de SOLETO MUÑOZ, «el siglo XXI está suponiendo en el ámbito de la Justicia

penal, un intento de enfocar la forma de administrar justicia con una nueva lente, la de la víctima. [...] La justicia del siglo XX consigue la tan necesitada garantía de los derechos del acusado, que puede ver mermadas sus libertades fundamentales, a través del proceso debido. En el siglo XXI, esta cuestión se considera superada y se evoluciona hacia la obtención de una Justicia de mayor calidad, que tenga en cuenta también la situación de la víctima» ${ }^{47}$.

La JR surge, en definitiva, como respuesta a la crisis del modelo rehabilitador, en un abordaje diferente al propuesto desde el neorretribucionismo o el abolicionismo, que busca ofrecer una alternativa frente a la constatación de carencias en la respuesta clásica al delito. En esta evolución, es claro el influjo de la cultura de la resolución pacífica de conflictos y el interés por la figura de la víctima, junto con el desarrollo de la victimología de la acción. Asimismo, el progreso de las concepciones restaurativas cuestiona las nociones utópicas y románticas de la Justicia que presentan a víctima y victimario como partes cuyos intereses resultan siempre y en todo caso irreconciliables ${ }^{48}$.

En ausencia de una definición válida universalmente, entendemos por JR siguiendo a RÍOS MARTÍN, «el método de resolver los conflictos que atiende prioritariamente a la protección de la víctima y al restablecimiento de la paz social, mediante el diálogo comunitario y el encuentro personal entre los directamente afectados, con el objeto de satisfacer de modo efectivo las necesidades puestas de manifiesto por los mismos, devolviéndoles una parte significativa de la disponibilidad sobre el proceso y sus eventuales soluciones, procurando la responsabilización del infractor y la reparación de las heridas personales y sociales provocadas por el delito» ${ }^{49}$.

(Madrid: Edisofer, 2008); Ignacio Flores Prada, «Algunas reflexiones sobre la justicia restaurativa en el sistema español de justicia penal», Revista Internacional de Estudios de Derecho Procesal y Arbitraje 2 (2015): 1-45. 47 Helena Soleto Muñoz, «Aportaciones internacionales al desarrollo de la Justicia restaurativa en España», en Justicia restaurativa, una justicia para el siglo XXI: potencialidades y retos, Cuadernos penales José María Lidón 9 (Bilbao: Deusto Digital, 2013), 81.

48 En torno al romanticismo y la utopía en relación con la reparación se refería Hirsch con estas palabras: «uno no consigue liberarse de la impresión de que la discusión sobre la reparación está acuñada también por concepciones algo románticas, a saber, por la suposición errónea de que autor y víctima están realmente, uno frente a otro, por regla, directamente, con sus intereses. Sin embargo, abstracción hecha de hacer valer el daño moral, éste no es, muy a menudo el caso». Vid. Hans Joachim Hirsch, «La reparación del daño en el marco del Derecho penal material», en De los delitos y de las víctimas, ed. Albin Esser, trad. Elena Carranza (Buenos Aires: Ad-Hoc, 1992), 114-15.

49 Julián Carlos Ríos Martín, «Justicia Restaurativa y mediación penal», Icade: Revista de las Facultades de Derecho y Ciencias Económicas y Empresariales 98, ejemplar dedicado a: La mediación como un sistema eficaz de solución de conflictos en todos los ámbitos (2016): 104-5. 
Revista Eletrônica de Direito Processual - REDP.

Rio de Janeiro. Ano 13. Volume 20. Número 3. Setembro a Dezembro de 2019

Periódico Quadrimestral da Pós-Graduação Stricto Sensu em Direito Processual da UERJ

Patrono: José Carlos Barbosa Moreira (in mem.). ISSN 1982-7636. pp. 51-74

www.redp.uerj.br

Si, con CUADRADO SALINAS, uno de los fines de la JR y la mediación penal es el de responder al interés de reparación de la víctima ${ }^{50}$, uno de los parámetros para medir el éxito de estos programas vendrá determinado por su capacidad para (a) ofrecer a la víctima un papel activo y relevante en la gestión de su conflicto, (b) un espacio adecuado para facilitar la expresión de emociones y la narración de su vivencia y (c) concretar las acciones de reparación que se hubieran podido consensuar durante las sesiones.

Para DOOLIN, la reparación desde la óptica restaurativa tiene un componente activo más fuerte que la reparación clásica, requiriendo un verdadero esfuerzo para restaurar a aquellos a quienes han alcanzado directamente los efectos de la infracción. Dicha reparación debería cubrir no solo los daños materiales si no también la vertiente emocional —reparación de la auto percepción de las víctimas, el sentimiento de seguridad y pertenencia o el empoderamiento de la víctima-. Para la autora, la comprensión íntegra de la reparación exige analizar no solo qué daños concretos deben ser reparados, sino la concreción de la reparación, a través - aunque no solo - de disculpas orales o escritas, la reparación a la víctima directa o a la comunidad, la restitución y la compensación ${ }^{51}$. En relación a este último punto, la práctica muestra entre los posibles acuerdos propuestas que varían desde la compensación económica y/o petición de disculpas a otras alternativas, igualmente válidas, centradas en la ejecución de tareas de reparación cara a la víctima individual o a la comunidad. Ahora bien, ni el perdón es el fin último de la mediación ni debe perseguirse a toda costa. Exigir el perdón de la víctima que accede a participar en un procedimiento restaurativo supone, primero, no tomar en cuenta el riesgo de victimización secundaria y después, una instrumentalización de la víctima a favor de unos intereses ajenos a los de JR.

El trabajo de AERTSEN y PETERS muestra un elevado grado de satisfacción general de las víctimas tras su paso por un programa de mediación, incluso en los casos en los que

\footnotetext{
50 Carmen Cuadrado Salinas, «La mediación: ¿una alternativa real al proceso penal?», Revista Electrónica de Ciencia Penal y Criminología 17 (2015): 14.

$51 \quad$ Para la autora, «Restorative justice is about restoring responsibility to offenders to take active steps to repair the harm caused, both materially and symbolically. Restorative justice is also about requiring offenders to participate in the process that decides how to deal with their offending behaviour. The aim should be to try and make offenders aware of the consequences of their actions and how the harm done affects others and themselves. In restorative processes, offenders have to speak about their offending and listen to how victims have been affected. The presence of victims means that it is harder for offenders to insulate themselves from the victim and rationalisations for their offending can be challenged more directly than what happens in the conventional criminal justice system».Vid. Katherine Doolin, «But What Does It Mean? Seeking Definitional Clarity in Restorative Justice», The Journal of Criminal Law 71, n. ${ }^{0} 5$ (2007): 432-33, https://doi.org/10.1350/jcla.2007.71.5.427.
} 
Revista Eletrônica de Direito Processual - REDP.

Rio de Janeiro. Ano 13. Volume 20. Número 3. Setembro a Dezembro de 2019

Periódico Quadrimestral da Pós-Graduação Stricto Sensu em Direito Processual da UERJ

Patrono: José Carlos Barbosa Moreira (in mem.). ISSN 1982-7636. pp. 51-74

www.redp.uerj.br

no hubo habido un contacto directo entre víctima y victimario. Para los autores, la satisfacción estaría directamente relacionada con el reconocimiento logrado respecto a ambas partes, así como a la posibilidad de contribuir activamente en la superación del conflicto de un modo que las partes percibieron como edificante. Entre los aspectos que las víctimas valoraron más positivamente figuran la reducción del miedo, mayor posibilidad de recibir algún tipo de compensación y una mejor valoración general del sentimiento respecto al sistema de justicia ${ }^{52}$.

\section{Algunas consideraciones finales}

Como se ha tratado de argumentar, la indagación en torno a los intereses de las víctimas pone de relieve la existencia de diferentes matices en las expectativas en función no solo del tipo de delito, también de la personalidad de la víctima o la reacción de su entorno más próximo. Es esta una de las cuestiones a tener en cuenta en el diseño de las políticas de asistencia, en tanto la respuesta óptima pasa necesariamente por la individualidad en el planteamiento de la intervención. En ocasiones sobresaldrá el deseo de la víctima de ser escuchada o de recibir las disculpas del infractor a partir, por ejemplo, de un encuentro directo víctima-victimario; en otras, en cambio, las víctimas desearán simplemente desentenderse del proceso y hacer uso de la vertiente negativa de ese derecho reconocida también en la LEVID. En definitiva, será la capacidad de respuesta ante diferentes experiencias y consecuentemente, también diferentes expectativas, uno de los factores definitorios en la calidad del servicio.

En este sentido, será esencial ofrecer a los profesionales en contacto con las víctimas formación actualizada para considerar e identificar esta pluralidad de intereses y la complejidad de los mismos; solo así se podrán comprender las razones detrás de una decisión favorable respecto a una participación activa en el proceso, el deseo (o no) de mantenerse informada $\mathrm{o}$, en definitiva, los intereses que subyacen a una actitud activa o pasiva respecto al proceso. Otros aspectos clave para el éxito de los servicios asistenciales serán la especialización de los profesionales, la coordinación y fluidez en la comunicación entre instituciones y los esfuerzos en favor de la visibilidad de las oficinas, así como la verdadera

$52 \quad$ Ivo Aertsen y Tony Peters, «Mediation for Reparation: The Victim’s Perspective», European Journal of Crime, Criminal Law and Criminal Justice 6, n. ${ }^{\circ} 2$ (1998): 117-24. 
Revista Eletrônica de Direito Processual - REDP.

Rio de Janeiro. Ano 13. Volume 20. Número 3. Setembro a Dezembro de 2019

Periódico Quadrimestral da Pós-Graduação Stricto Sensu em Direito Processual da UERJ

Patrono: José Carlos Barbosa Moreira (in mem.). ISSN 1982-7636. pp. 51-74

www.redp.uerj.br

inversión en programas de Justicia restaurativa, que pongan a disposición de los usuarios del sistema de Justicia mecanismos de gestión adecuada de conflictos.

\section{REFERENCIAS:}

Aertsen, Ivo, y Tony Peters. «Mediation for Reparation: The Victim's Perspective». European Journal of Crime, Criminal Law and Criminal Justice 6, n. 2 (1998): 10624.

Bolívar, Daniela. «La víctima en la Justicia restaurativa: reflexiones desde una perspectiva psico-social». En Jornadas de Justicia Restaurativa, de Inés Olaizola Nogales y Paz Francés Lecumberri. Navarra: Ediciones Universidad Pública de Navarra, 2011.

Boom, Annemarie ten, y Karlijn F. Kuijpers. «Victims' Needs as Basic Human Needs». International Review of Victimology 18, n. ${ }^{\circ} 2$ (2012): 155-79.

Bouffard, Leeana A., Matt R. Nobles, Amanda Goodson, Kade Brinser, Maria Koeppel, y Miner P. Marchbanks. «Service Providers' Knowledge and Perceptions of the Legal Service Needs of Crime Victims». American Journal of Criminal Justice 42, n. ${ }^{\circ} 3$ (2017): 589-609.

Christopher, Bennet. «Satisfying the Needs and Interests of Victims». En Handbook of Restorative Justice, de Johnstone Gerry y Van Ness Daniel W., 247-64. Devon: Willan Publishing, 2007.

Cobb, Sara. Hablando de violencia. La política y las poéticas narrativas en la resolución de conflictos. Traducido por María Natalia Prunes y Cecilia Sobrón. 1. ${ }^{a}$ ed. Barcelona: Gedisa editorial, 2016.

Cuadrado Salinas, Carmen. «La mediación: ¿una alternativa real al proceso penal?» Revista Electrónica de Ciencia Penal y Criminología 17 (2015).

Daly, Kathleen. «Sexual violence and victims’ justice interests». En Restorative Responses to Sexual Violence. Legal, Social and Therapeutic Dimensions, de Estelle Zinsstag y Marie Keenan, 108-39, 1. ${ }^{a}$ ed. Great Britain: Routledge, 2017.

Daza Bonachela, $\mathrm{M}^{\mathrm{a}}$ del Mar. «Victimología hoy, derecho victimal europeo y español y atención a las víctimas de delitos en España». Universidad de Granada. Departamento de Derecho Penal., 2014. digibug.ugr.es/bitstream/10481/34696/1/24310402.pdf.

DeValve, Elizabeth Quinn. «A Qualitative Exploration of the Effects of Crime Victimization 
Revista Eletrônica de Direito Processual - REDP.

Rio de Janeiro. Ano 13. Volume 20. Número 3. Setembro a Dezembro de 2019

Periódico Quadrimestral da Pós-Graduação Stricto Sensu em Direito Processual da UERJ

Patrono: José Carlos Barbosa Moreira (in mem.). ISSN 1982-7636. pp. 51-74

www.redp.uerj.br

for Victims of Personal Crime». Applied Psychology in Criminal Justice 1, n. ${ }^{0} 2$ (2005): 71-89.

Doolin, Katherine. «But What Does It Mean? Seeking Definitional Clarity in Restorative Justice». The Journal of Criminal Law 71, n. ${ }^{\circ} 5$ (2007): 427-40. https://doi.org/10.1350/jcla.2007.71.5.427.

Echeburúa, Enrique, y Paz De Corral. «Intervención en crisis en víctimas de sucesos traumáticos: ¿cuándo, cómo y para qué?» Psicologóa Conductual 15, n. 3 (2007): 373 87.

Echeburúa Odriozola, Enrique, y Paz De Corral. «Especial consideración de algunos ámbitos de victimación». En Manual de Victimología, de Enrique Baldomero Baca Baldomero, Enrique Echeburúa Odriozola, y Josep María Tamarit Sumalla, 129-206. Valencia: Tirant lo Blanch, 2006.

Elias, Robert. «Paradigms and Paradoxes of Victimology». En International Victimology: Selected Papers from the 8th International Symposium. AIC conference proceedings., editado por Chris Sumer, Michael O’Connell, Rick Sarre, y Mark Israel. Canberra: Australian Institute of Criminology, 1996. https://aic.gov.au/publications/proceedings/27.

Ferreiro Baamonde, Xulio. La víctima en el proceso penal. 1 ${ }^{\text {a }}$. Madrid: La Ley, 2005.

Fisher, Roger, y William Ury. Getting to Yes: Negotiating Agreement without Giving In. 1. ${ }^{\mathrm{a}}$ ed. New York: Penguin, 1981.

Flores Prada, Ignacio. «Algunas reflexiones sobre la justicia restaurativa en el sistema español de justicia penal». Revista Internacional de Estudios de Derecho Procesal y Arbitraje 2 (2015): 1-45.

Heather, Strang. Repair or Revenge: Victims and Restorative Justice. Clarendon Press, 2004.

Herrera Moreno, Myriam. La hora de la víctima: compendio de victimología. Vol. 73. Madrid: Edersa, 1996.

—. «Sobre víctimas y victimidad. Aspectos de controversia científica en torno a la condición de víctima». En Víctima, prevención del delito y tratamiento del delincuente, de Antonio García-Pablos de Molina, 75-109, 1ª. Estudios de Derecho Penal y Criminología. Granada: Comares, 2009.

Hirsch, Hans Joachim. «La reparación del daño en el marco del Derecho penal material». En De los delitos y de las víctimas, editado por Albin Esser, traducido por Elena 
Revista Eletrônica de Direito Processual - REDP.

Rio de Janeiro. Ano 13. Volume 20. Número 3. Setembro a Dezembro de 2019

Periódico Quadrimestral da Pós-Graduação Stricto Sensu em Direito Processual da UERJ

Patrono: José Carlos Barbosa Moreira (in mem.). ISSN 1982-7636. pp. 51-74

www.redp.uerj.br

Carranza, 53-90. Buenos Aires: Ad-Hoc, 1992.

Holder, Robyn L. «Just Interest: Victims, Citizens and the Potential for Justice». Australia

National University, 2013. https://openresearch-

repository.anu.edu.au/bitstream/1885/.../1/Holder_R.L._2013L.pdf.

Joutsen, Matti. The Role of the Victim of Crime in European Criminal Justice Systems: A Crossnational Study of the Role of the Victim. Helsinki: Heuni, 1987.

Landrove Díaz, Gerardo. La moderna victimología. Valencia: Tirant lo Blanch, 1998.

Lazarus, Lazarus S., y Susan Folkman. Stress, Appraisal and Coping. Nueva York: Springer Publishing Company, Inc., 1984.

Leal Medina, Julio. «Régimen jurídico de la víctima del delito. Normativa presente y de futuro. Derechos en el proceso penal y en las leyes extraprocesales. Especial atención al Anteproyecto de la Ley Orgánica del Estatuto de la víctima del delito.» Diario La Ley 8287 (4 de julio de 2014).

Lorente, Lourdes, y Roberto Moreno. «El servicio de atención a la víctima (SAV) como elemento fundamental del sistema de justicia restaurativa del Gobierno Vasco». En Victimología: en busca de un enfoque integrador para repensar la intervención con víctimas, de Gema Varona Martínez, 161-86, 1ª Navarra: Thomson Reuters-Aranzadi, 2018.

Maguire, Mike. «The Needs and Rights of Victims of Crime». Crime and justice 14 (1991): 363-433.

Martínez Soto, Tamara. «Justicia restaurativa y terrorismo: la reparación de las víctimas del terrorismo en España». Universidad Carlos III de Madrid, 2016. http://hdl.handle.net/10016/22564.

Maslow, Abraham H. Motivación y personalidad. Traducido por Claridad Clemente. Madrid: Ediciones Díaz de Santos, 1991.

Morillas Fernández, David L., Rosa M. Patró Hernández, y Marta M. Aguilar Cárceles. Victimología: un estudio sobre la víctima y los procesos de victimización. Madrid: Dykinson, 2011.

—. Victimología: un estudio sobre la víctima y los procesos de victimización. Madrid: Dykinson, 2011.

Orth, Uli. «Secondary Victimization of Crime Victims by Criminal Proceedings». Social Justice Research 15, n. ${ }^{\circ}$ (2002): 313-25. 
Revista Eletrônica de Direito Processual - REDP.

Rio de Janeiro. Ano 13. Volume 20. Número 3. Setembro a Dezembro de 2019

Periódico Quadrimestral da Pós-Graduação Stricto Sensu em Direito Processual da UERJ

Patrono: José Carlos Barbosa Moreira (in mem.). ISSN 1982-7636. pp. 51-74

www.redp.uerj.br

Ortuño Muñoz, José-Pascual, y Javier Hernández García. Sistemas alternativos a la resolución de conflictos (ADR): la mediación en las jurisdicciones civil y penal. Fundació alternativas, 2007.

Pemberton, Antony, Rianne Letschert, y Ines Staiger. Assisting Victims of Terrorism: Towards a European Standard of Justice. 1. Aufl. Springer Netherlands, 2010.

Pillado González, Esther. «La justicia terapéutica y sus manifestaciones en el proceso penal español». En Mediación, arbitraje y jurisdicción en el actual paradigma de justicia, de Silvia Barona Vilar, 251-76, 1. ${ }^{\mathrm{a}}$ ed. Navarra: Thomson Reuters-Civitas, 2016.

Ríos Martín, Julián Carlos. «Justicia Restaurativa y mediación penal». Icade: Revista de las Facultades de Derecho y Ciencias Económicas y Empresariales 98, n. ${ }^{\circ}$ Ejemplar dedicado a: La mediación como un sistema eficaz de solución de conflictos en todos los ámbitos (2016): 103-26.

Schaefer Morabito, Melissa, April Pattavina, y Linda M. Williams. «It All Just Piles Up: Challenges to Victim Credibility Accumulate to Influence Sexual Assault Case Processing». Journal of Interpersonal Violence, 2016, 1-20. https://doi.org/DOI: $10.1177 / 0886260516669164$.

Soleto Muñoz, Helena. «Aportaciones internacionales al desarrollo de la Justicia restaurativa en España». En Justicia restaurativa, una justicia para el siglo XXI: potencialidades y retos, 77-106. Cuadernos penales José María Lidón 9. Bilbao: Deusto Digital, 2013.

—. «La conferencia Pound y la adecuación del método de resolución de conflictos». Revista de Mediación 10, n. ${ }^{\circ} 1$ (2017): 1-6. https://revistademediacion.com/articulos/laconferencia-pound-la-adecuacion-del-metodo-resolucion-conflictos/.

Stokkom, Bas van. «Victims' Needs and Participation in Justice: Is There a Role for Vengeance?» Restorative Justice: An International Journal 1, n. ${ }^{\circ} 2$ (2013): 168-89. https://doi.org/10.5235/20504721.1.2.168.

Ury, William, Jeanne M. Brett, y Stephen B. Goldberg. Getting Disputes Resolved. Designing Systems to Cut the Cost of Conflict. 1. ${ }^{\mathrm{a}}$ ed. San Francisco: Jossey-Bass Inc. Publishers, 1988.

Waller, Irvin. Rebalancing Justice. Rights for victims of crime. $1 .^{\text {a }}$ ed. Rowman \& littlefield publishers, 2011.

Zaragoza Aguado, Javier-Alberto. «La víctima y su protección asistencial en el Derecho español». En Recurso de amparo, cuestión de inconstitucionalidad y cuestión 
Revista Eletrônica de Direito Processual - REDP.

Rio de Janeiro. Ano 13. Volume 20. Número 3. Setembro a Dezembro de 2019

Periódico Quadrimestral da Pós-Graduação Stricto Sensu em Direito Processual da UERJ

Patrono: José Carlos Barbosa Moreira (in mem.). ISSN 1982-7636. pp. 51-74

www.redp.uerj.br

prejudicial europea. Protección a la víctima. Perspectiva sociológica, asistencial y jurídica., 2:295-342. Estudios jurídicos. Ministerio Fiscal. Madrid: Ministerio de Justicia. Centro de Estudios Jurídicos de la Administración de Justicia, 2000. 